A2

doi: 10.14232/fgykf.2018.a2

\title{
Phytochemical investigation of Euphorbia matabelensis
}

\section{Reham Hammadi, Norbert Kúsz, Judit Hohmann, Andrea Vasas}

University of Szeged, Department of Pharmacognosy, 6720 Szeged, Eötvös u. 6.

For centuries, Euphorbia species have been used by various civilizations as sources of different medicines, due to their marked physiological effects. Diterpene-containing plants of the family Euphorbiaceae are of considerable interest as concerns natural product drug discovery programs because of the wide range of potentially valuable biological activities and the broad structural diversity due to the different polycyclic and macrocyclic skeletons and various aliphatic and aromatic ester groups. However, other compounds, e.g. triterpenes, steroids, and flavonoids can also contribute their diverse pharmacological activities.

In continuation of our investigations on phytochemistry of Euphorbia species, Euhorbia matabelensis was investigated. This succulent tree is native to Africa and use to treat e.g. depression, high blood pressure, swollen lymph glands, as a purgative in case of poisoning, and to induce abortion. After multiple separation process, including vacuum liquid chromatography, preparative TLC, and HPLC, one diterpene (ingenol) and two flavonoids (naringenin and eriodictyol) were obtained from the chloroformsoluble fractions of the methanol extracts prepared from the stem and root of the plant. The structure elucidation was performed by extensive spectroscopic analysis, including $1 \mathrm{D}$ and $2 \mathrm{D} \mathrm{NMR}\left({ }^{1} \mathrm{H}-{ }^{1} \mathrm{H}\right.$ COSY, HSQC, and $\left.\mathrm{HMBC}\right)$, and MS experiments, and comparing them with literature data. All compounds were isolated for the first time from the plant.

Acknowledgement: This work was supported by the Ministry of Human Capacities, Hungary grant 203913/2018/FEKUSTRAT.

Supervisor: Andrea Vasas 